\title{
COMPARATIVE EFFICACY, SAFETY AND TOLERABILITY OF OLANZAPINE AND BLONANSERIN IN PATIENTS WITH SCHIZOPHRENIA: A PARALLEL GROUP STUDY
}

\author{
S. Chattopadhyay ${ }^{1}$, U. Roy ${ }^{2}$, S. Biswas ${ }^{1}$, P. Roy ${ }^{3}$, P. Mandal ${ }^{4}$ \\ ${ }^{1}$ Department of Pharmacology, Burdwan Medical College and Hospital - India \\ ${ }^{2}$ Department of Pharmacology, Raiganj Govt. Medical College and Hospital - India \\ ${ }^{3}$ Department of Psychiatry, Burdwan Medical College and Hospital - India \\ ${ }^{4}$ Department of Pharmacology, Raiganj Govt. Medical College and Hospital - India
}

\begin{abstract}
Background: The antipsychotic olanzapine is a first-line drug in the treatment of schizophrenia while blonanserin is indicated in resistant cases of schizophrenia when the first line antipsychotics have failed. There are very limited studies available worldwide as well as in India that compare blonanserin with other antipsychotics in the setting of schizophrenia. Aims: To study the efficacy, safety and tolerability of olanzapine and blonanserin in Schizophrenia. Settings and Design: The study was a prospective, observational, parallel group study done on schizophrenia patients aged between 18-50 years of both sexes at an outpatient Department of Psychiatry, in a tertiary medical college. The study was conducted from February 2015 to October 2016, with follow ups at weeks 4, 8 and 12. Materials and Methods: The efficacy parameters were measured by the Brief Psychiatric Rating Scale (BPRS) and the Clinical Global Impression (CGI) rating. The safety parameters included the vital signs, haematological profile, lipid profile, blood sugar monitoring. Adverse drug reactions and compliance to therapy was observed throughout the study period. Appropriate statistical tests were applied to detect any significant within and between group differences using Microsoft Excel 2007 and SPSS version 17. Results: There was significant decrease in the mean total score on the BPRS and CGI-S in the blonanserin arm at the 2 nd and last follow up visit ( $p$ value $<0.001)$. Compliance was good in both groups ( $\leq 20 \%$ missed pills). Overall, 77 treatment-emergent adverse events were present from 56 patients. Twenty three subjects of the blonanserin arm and 33 subjects in the olanzapine arm at least experienced one adverse event $(p=$ 0.006), metabolic adverse effects were more common with olanzapine, whereas insomnia, headache and somnolence were more often seen with blonanserin. Conclusions: In the present study, blonanserin provided significantly better outcomes than olanzapine with respect to BPRS, CGI-S scores.
\end{abstract}

Key words: blonanserin, efficacy, olanzapine, safety, schizophrenia, tolerability

Corresponding Author: Dr. Uttam Kumar Roy, Dilip Das Sarani, Hill View Main, Paschim Bardhaman, Pin-713304, West Bengal, India, Phone numbers: 9434163225, E-mail: uroy951@gmail.com

RECEIVED: 11 August 2020, ACCEPTED: 29 September 2020 


\section{INTRODUCTION}

$\mathrm{S}$ chizophrenia is a chronic psychiatric disorder characterised by positive symptoms, negative symptoms and cognitive impairment. Global prevalence of schizophrenia is $1 \%$ and the incidence remains 1.5 per 10000 population [1]. In India, the weighted prevalence of schizophrenia is $0.64 \%$ [2]. Schizophrenia patients suffer of higher morbidity and mortality [3]. Though pharmacotherapy is the mainstay of therapy, psychotherapy is also important. Antipsychotics like olanzapine used as 1st line agent for pharmacotherapy of schizophrenia, provide effective control for positive symptoms but the negative symptoms and cognitive impairment remain a challenge for social functioning, subjective well-being and long-term adherence to therapy. Second generation antipsychotic drugs should then be prescribed according to Canadian guidelines [4] which categorized recommendations into six areas.

The other challenges for therapy are non-adherence to therapy, social stigma, substance abuse, suicidal tendency and comorbidities. Atypical antipsychotics like blonanserin, having high affinity for D2, D3 and $5 \mathrm{HT} 2 \mathrm{~A}$ receptors, are helpful in controlling negative symptoms and cognitive impairment as shown in animal studies as well as in humans [5, 6]. But these drugs are not free from adverse effects that limit effectiveness and compliance [7]. The atypical antipsychotic drugs have better safety profile [8]. Olanzapine is commonly used as a first-line drug in the treatment of acute symptoms and for maintenance therapy but its role in treating negative symptoms remains unclear [9]. Recent studies have shown that this drug is likely to induce weight gain and an increased risk for obesity-related diseases, as well as metabolic syndrome [10]. Olanzapine usewas associated with hyperglycaemia [11]. Blonanserin is unlikely to cause metabolic side effects, is generally well tolerated and can cause less prolactin elevation [12]. It also improves cognitive function in patients with first-episode and chronic schizophrenia [13]. But there is a need of comparing blonanserin with other antipsychotics in schizophrenia in Indian patients. Global reports are also limited. Thus, the aim of this study was to compare efficacy, safety and tolerability of blonanserin for long term management compared with a standard atypical antipsychotic such as olanzapine.

\section{MATERIALS AND METHODS}

\section{Study design and subjects}

The study was a prospective, observational, controlled, parallel group, comparing blonanserin versus a standard atypical antipsychotic, Olanzapine.
Being an observational study, CTRI approval was not required. Ethics Committee approval was obtained prior to study from the appropriate Clinical Research Ethics Committee [BMC/PG/190/1(1), Dated10/01/2015]. Patients presenting with history or symptoms of schizophrenia were screened and recruited as per subject selection criteria. Recruitment was subjected to satisfactory completion of the informed consent process. Laboratory parameters were assessed at baseline and at end of 4 weeks.

\section{Inclusion criteria}

All patients aged between 18 and 50 years of both sexes diagnosed with schizophrenia by the Structured Clinical Interview for DSM IV Axis-1 Disorders (SCID) and. The SCID has been used by most of the studies for diagnosis of schizophrenia. The SCID is an efficient, user-friendly and reliable clinical interview for making DSM diagnosis [14]. Patients with normal complete blood counts, blood sugar, lipid profile and normal ECG were included in the study.

\section{Exclusion criteria}

Pregnant and lactating women, immunosuppression due to drug or disease, severe psychosis and violent behaviour; patients who have already taken any other antipsychotic or antidepressant medication, presence of renal or hepatic impairment, substance abuse, participation in any other clinical trial within past 3 months, patients unable or not willing to give consent, diseases of vital organs, those receiving medications known to prolong QT-interval or capable of otherwise having drug-drug interaction with study medication.

\section{Time schedule of visits and activities at each visit}

Subjects were screened in the psychiatry outpatient department and the diagnosis was done by the Structured Clinical Interview for DSM IV Axis-1 Disorders (SCID) [14]. In addition, the selection criteria were checked and written informed consent was obtained from the patient. Laboratory examination included parameters such as haemoglobin $(\mathrm{Hb})$, total leucocyte count (TLC), differential count (DLC), erythrocyte sedimentation rate (ESR), random blood sugar (RBS), blood lipid profile, plus blood pressure and ECG.

Concomitant medication was noted and non-permitted medications were withdrawn prior to the study. The baseline visit was scheduled five days after the screening visit to allow for any antipsychotic that had been taken to be washed out. The period of five days reflected the five half-lives of the commonly prescribed antipsychotic agents [15]. The dosage of Blonanserin 
was 8-12 mg daily in two divided doses - with titration up to $24 \mathrm{mg}$ [16]. The clinical pharmacokinetic profile of olanzapine supported once-daily oral administration, starting with a dose of 5-10 mg, with a target dose of 10 $\mathrm{mg} / \mathrm{day}$, and a maximum dose of $20 \mathrm{mg} /$ day [17].

Patients were asked to report immediately any unwanted and unexpected reactions. They were followed up at weeks 4,8 and 12 with possibility for interim follow up for assessing adverse events, if needed.

\section{Measurements}

The Brief Psychiatric Rating Scale (BPRS) [18] and the Clinical Global Impression (CGI) Severity [19] were measured at baseline, 4th week, 8th week and 12th week. The BPRS assesses several symptom domains due to the multidimensional nature of the scale. Psychometric investigations of various BPRS versions provide evidence for satisfactory to excellent inter-rater reproducibility [20].

CGI Severity and improvement scales offer a readily understood, practical measurement tool, thus can be easily administered by a clinician in a busy clinical practice setting to document the details, track responses to interventions and monitor and quantify patient progress [21].

Recorded adverse events included treatment-emergent events reported spontaneously by subjects at any time during the 12-week treatment. Causality analysis of adverse events was done by using the WHO-UMC Scale [22]. Compliance with therapy was assessed by the pill counting method.

Adherence to therapy was considered satisfactory if $\leq 20 \%$ pills were missed [23].

\section{Statistical considerations}

The target sample was 33 in each group. This was calculated to detect a difference between groups of 6 in the Brief Psychiatric Rating Scale (BPRS) score with $80 \%$ power and $5 \%$ probability of Type 1 error, assuming a standard deviation of 10 for the same parameter. Considering a $20 \%$ drop-out rate, the number of patients required to be recruited in each group is 40 or 80 subjects overall.

Students independent t-tests were applied for age, and chi-square test for sex distribution, residence, literacy, occupation. Within-group analysis was done by Friedman ANOVA followed by post hoc analysis with Multiple Wilcoxon Signed Ranks test with a Bonferroni correction.

\section{RESULTS}

A total of 110 patients attending the out-patient Department of Psychiatry were screened for this study.
Among them 80 were finally randomised -40 in each group. Of these, three patients were lost to followup, of which two from the blonanserin group and one from the Olanzapine group. 77 patients (39 in blonanserin group and 38 in Olanzapine group) fulfilled modified-intention-to-treat criteria [23] and their parameters were analyzed (Fig. 1). The demographic characteristics (Table 1) of both groups were comparable at baseline. The clinical characteristics of the subjects in both groups were comparable at baseline. (Mann-Whitney U-test).

Within group analysis showed that the mean total score of BPRS decreased significantly in both groups: with blonanserin from baseline $(61.18+$ $4.29)$ to week $12(27.10+3.57, p<0.001)$, olanzapine from baseline $(60.13+4.23)$ to week $12(31.61+$ 4.04, $p<0.001$ ) (fig. 2). The CGI-S score decreased from baseline $(5.13+0.61)$ at 12 weeks $(1.72+0.51)$ in Blonanserin group $(n=39)$ ( $p$ value $<0.001)$. In the Olanzapine Group $(n=39)$ the reduction was from $5.03+0.59$ at baseline to $2.16+0.49$ at 12 weeks $(p$ $<0.001$ (fig. 3).

Inter-group analysis (Independent-Sample t test) revealed that the BPRS score and CGI-S score were declining over the treatment period in both groups. This decline was statistically significant $(p<.001)$ when compared between visits of the both treatment arms in second and end follow up visit [Tables 2 and 3].The end-of-study compliance (per protocol) assessment indicateed excellent adherence to treatment for all patients in both treatment groups ( $\leq 20 \%$ missed dose).

Not a single participant encountered a serious adverse event and there were no hospitalizations. During the 12-week study period a total of 68 subjects were suspected of having at least one adverse drug reaction (ADR). On causality assessment, 12 of these 68 cases (17.65\%) were considered with WHO-UMC causality status" unlikely". From the remaining 56 subjects, 77 ADRs $(93.5 \%)$ belonged to the "probable" category, whereas 5 (6.49\%) were of "possible" type according to the WHO-UMC scale. No case could be labelled "certain", as re-challenge was not attempted by the attending psychiatrist, once a drug was withdrawn. Overall, out of 77 treatmentemergent adverse events from 56 patients: 23 subjects in the Blonanserin arm and 33 subjects in the Olanzapine arm reported at least one event. (Table 2) ( $p=0.006$ by chi-square test). 
Table 1. Demographic profile of the study population $(N=77)$

\begin{tabular}{|l|c|c|}
\hline Categry & Blonanserin group $(\mathbf{n}=\mathbf{3 9})$ & Olanzapine group $(\mathbf{n}=\mathbf{3 8})$ \\
\hline Age $($ Years $)$ & 18 to 50 & 18 to 50 \\
Mean \pm SD & $31.51 \pm 5.86$ & $32.66 \pm 7.14$ \\
\hline Gender & & \\
Male & $56.4 \%$ & $47.4 \%$ \\
Female & $43.6 \%$ & $52.6 \%$ \\
\hline
\end{tabular}

Table 2. Changes in the BPRS score over 12 weeks

\begin{tabular}{|l|c|c|c|}
\hline BPRS & $\begin{array}{c}\text { Blonanserin group } \\
(\mathbf{n}=39) \\
\text { Mean } \pm \text { SD }\end{array}$ & $\begin{array}{c}\text { Olanzapine group } \\
(\mathbf{n}=38) \\
\text { Mean } \pm \text { SD }\end{array}$ & $\begin{array}{c}\mathbf{p} \text { value } \\
\text { (between groups) }\end{array}$ \\
\hline Baseline & $61.18 \pm 4.29$ & $60.13 \pm 4.23$ & 0.284 \\
\hline 1st follow-up & $54.00 \pm 3.33$ & $54.53 \pm 3.65$ & 0.511 \\
\hline 2nd follow-up & $38.10 \pm 3.06$ & $44.11 \pm 4.11$ & $<0.001$ \\
\hline End of study & $27.10 \pm 3.57$ & $31.61 \pm 4.04$ & $<0.001$ \\
\hline
\end{tabular}

Table 3. Changes in the CGI-S score over 12 weeks

\begin{tabular}{|l|c|c|c|}
\hline CGI-S & $\begin{array}{c}\text { Blonanserin group } \\
(\mathbf{n}=39) \\
\text { Mean } \pm \text { SD }\end{array}$ & $\begin{array}{c}\text { Olanzapine group } \\
(\mathbf{n}=38) \\
\text { Mean } \pm \text { SD }\end{array}$ & $\begin{array}{c}\text { p value } \\
\text { (between groups) }\end{array}$ \\
\hline Baseline & $5.13 \pm 0.61$ & $5.03 \pm 0.59$ & 0.452 \\
\hline 1st follow-up & $4.41 \pm 050$ & $4.42 \pm 0.50$ & 0.924 \\
\hline 2nd follow up & $2.87 \pm 0.41$ & $3.45 \pm 0.50$ & $<0.001$ \\
\hline End of study & $1.72 \pm 0.51$ & $2.16 \pm 0.49$ & $<0.001$ \\
\hline
\end{tabular}

Table 4. Individual reported adverse drug reactions

\begin{tabular}{|l|c|c|c|}
\hline Adverse event & $\begin{array}{c}\text { Blonanserin group } \\
(\mathbf{n}=\mathbf{3 9 )}\end{array}$ & $\begin{array}{c}\text { Olanzapine group } \\
(\mathbf{n}=\mathbf{3 8})\end{array}$ & $\begin{array}{c}\mathbf{p} \text { value } \\
(\text { between groups })\end{array}$ \\
\hline Insomnia & 8 & 4 & 0.227 \\
\hline Somnolence & 7 & 4 & 0.352 \\
\hline Nausea & 2 & 7 & 0.087 \\
\hline Tremor & 2 & 4 & 0.431 \\
\hline Anxiety & 5 & 5 & 1.000 \\
\hline Headache & 4 & 0 & 0.115 \\
\hline Vomiting & 1 & 6 & 0.056 \\
\hline Constipation & 0 & 2 & 0.240 \\
\hline Weight gain & 3 & 10 & 0.675 \\
\hline Increased salivation & 0 & 1 & 0.494 \\
\hline Akathisia & 0 & 2 & 0.240 \\
\hline
\end{tabular}

(Chi-square test for insomnia and somnolence and Fisher's exact test for the rest) 


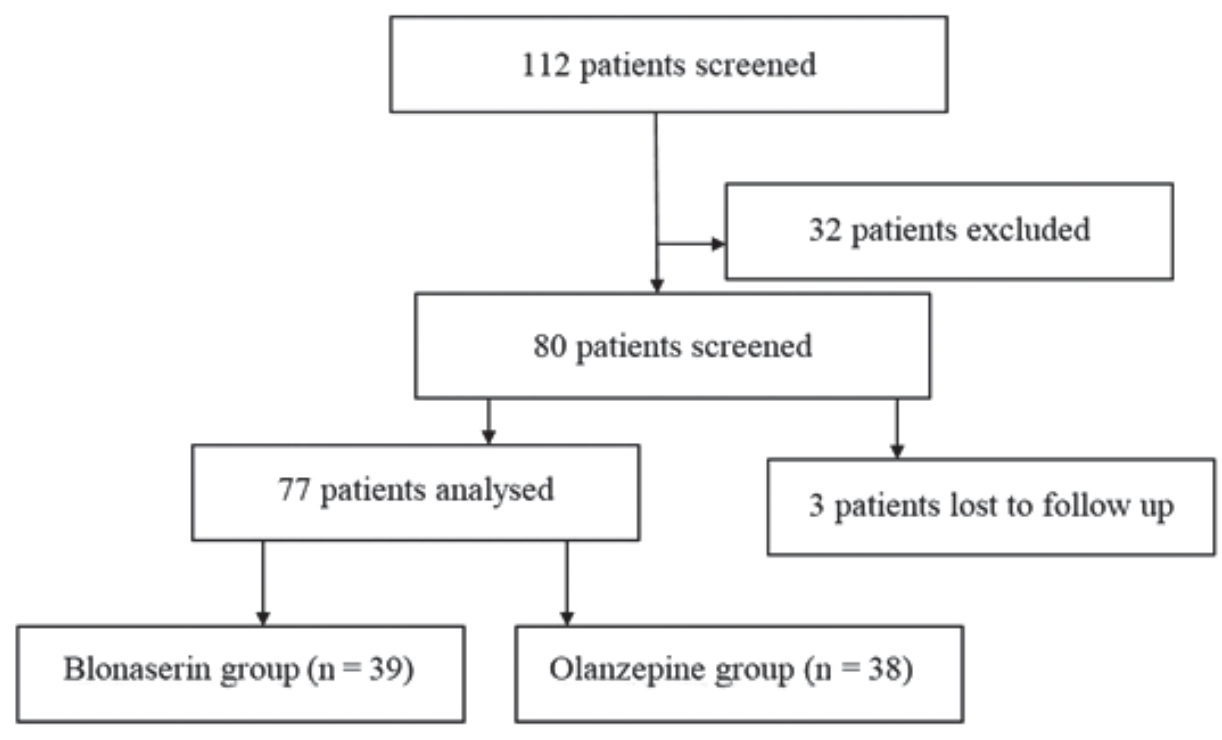

Fig. 1. Study subjects recruitment flow chart

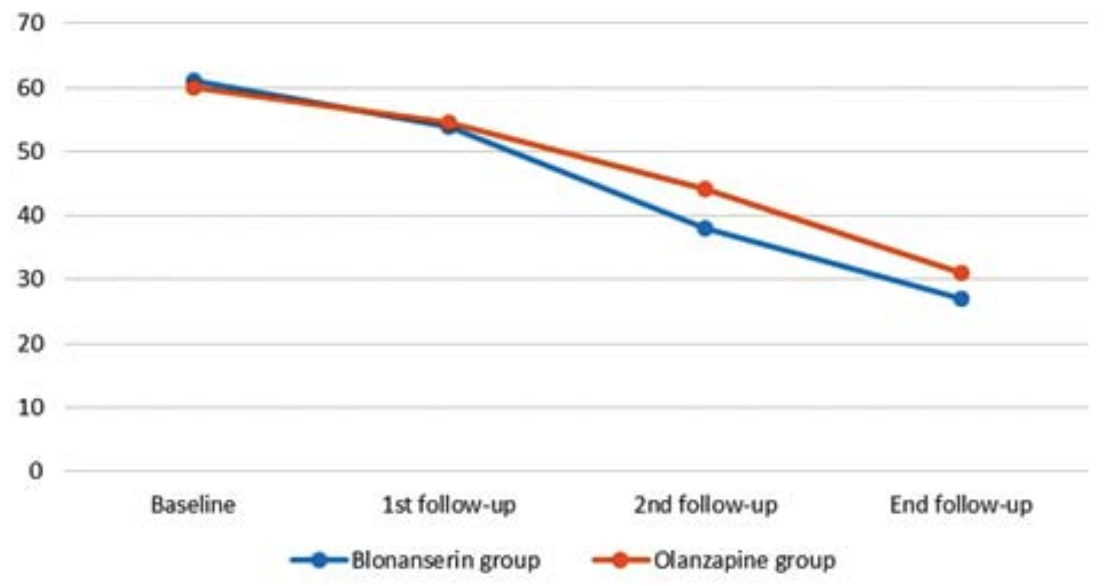

Fig. 2. The BPRS score at different visits in two treatment arms

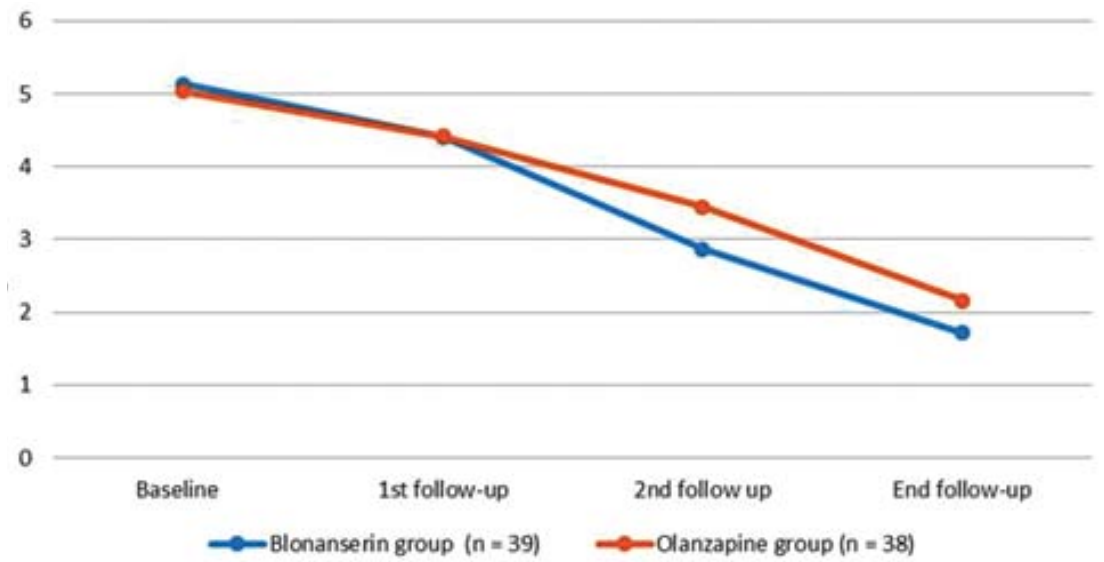

Fig. 3. The CGI-S score at different visits in two treatment arms

DISCUSSION

Schizophrenia is a functionally and socially debilitating chronic psychiatric illness that necessitates long term therapy at a high cost. Second generation antipsychot- ics are the best options when efficacy, safety and tolerability profiles are concerned [24] and this study is trying to find a new option. We found no study that compared the two drugs olanzapine and blonanserin in the treatment of schizophrenia globally and in our country. 
Patients having severe psychosis or severe disease condition were excluded from our as those subjects would be very difficult to handle. The study subjects were assessed in four visits which helped thorough assessment of the patients regarding efficacy, safety and adverse drug reactions. There were no significant difference in the duration of illness of both groups (blonanserin - $21.15 \pm 5.48$ months, olanzapine $-22.37 \pm 5.29$ months, $p$ value 0.270 ). The majority of subjects in our study belonged to younger age groups because of the wide prevalence of the disease in younger age [1] and so other co-morbidities associated with advanced age were avoided. Our study showed that most of the patients were in their thirties with a nearly equal gender distribution. The WHO statistics also found a greater incidence of schizophrenia in the third decade of life, though males were shown to be suffering more often from the disease [1]. This difference can be due to a small sample size in our population. Other demographic profiles were comparable in both treatment arms.

The vital signs recorded at baseline were analogous in both the treatment arms. The laboratory parameters were within normal limits in both groups.

Regarding efficacy, the BPRS scale (a short version of PANSS) [25] and the CGI-S showed significant improvement from 2nd follow-up visits to end of study visit in the blonanserin group compared to the olanzapine group. Woo YS (2019) showed significant reduction in BPRS that support our study findings [26]. Another study of Woo YS (2016) showed significant reduction in CGI-S with blonanserin [27].

Blonanserin induced improvement in the negative symptoms and cognitive impairment with less adverse effects in various short and long term studies [28]. It has been shown that cognition improvement more than 0.5 SD improves quality of life [29]. In the present study, blonanserin induced a significantly better outcome as assessed by the BPRS and CGI$S$ scores. We found no study compared blonanserin with olanzapine in therapy of schizophrenia, but other studies with other antipsychotics showing superior efficacy of blonanserin compared with haloperidol [30], risperidone [31], aripiprazole [32], amisulpuride [33].

When safety parameters were considered (vital signs such as the pulse rate, systolic and diastolic blood pressure), they were comparable at baseline and at treatment end in both medication groups. In the current study, an increase in haemoglobin in both the treatment groups was registered, however between groups comparisons did not reveal any relation. The mean values of other haematological parameters did not vary at baseline and end of study visits in either of the two treatment arms. No other studies corroborated with this observations [6].

In respect to lipid profile tests there were significant increases of post treatment mean values of total cholesterol, triglycerides, LDL-cholesterol, VLDLcholesterol and a significant decrease of post treatment mean values of HDL-cholesterol in both treatment arms. In between groups comparisons all the biochemical parameters were comparable except for serum total cholesterol, which was increased more at study end by olanzapine than by Blonanserin. This highlighted the need for checking their lipid profile every 3 months when administering these medications. Studies done by Huh L, Lee BJ (2019) [34] and Lally J, MaCabe JH (2015) [8] support our findings. The random blood glucose levels at baseline and studyend were comparable - both within and in-between the two treatment arms. However, many studies showed a strong association of olanzapine with the incidence of type 2 diabetes mellitus [34].

The treatment-emergent side effects are depicted in table 4. The patients in both groups complained of many adverse events from which $93.5 \%$ were ADRs belonging to the "probable" category, whereas $6.5 \%$ fell in the "possible" category, according to the WHOUMC causality assessment scale [35]. The incidence of adverse events was significantly higher in the olanzapine arm in which weight gain, Gl disturbances were more common. On the other hand, insomnia, somnolence, headache were more frequently reported by Blonanserin treated patients. The incidence of anxiety was equal in both treatment arms. The RCT done by Gründer, Gerhard \& Heinze in 2016 revealed similar findings also [24].

Blonanserin, an atypical antipsychotic with dopamine D3, D2, 5HT2A receptor antagonism has proved to be effective in the management with least metabolic, extrapyramidal and hyperprolactinaemic side effects. Blonanserin does not produce sedation due to its low affinity for the $5 \mathrm{HT} 2 \mathrm{C}$, adrenergic alpha1, histamine $\mathrm{H} 1$ and muscarinic $\mathrm{M} 1$ receptors [36]. Switching to blonanserin can reverse medication - induced hyperprolactinemia found in female patients making it is a suitable antipsychotic [12].

Study subjects showed good compliance to therapy as there were $\leq 20 \%$ missed doses in both groups. The lack of troublesome adverse events helped in this regard. Also, most of them (both patients and family members) were well educated to understand the nature of the disease and the medication effect. In addition, good communication could be established before signing the consent form. This may be also due to small sample size. Such compliance in 
the patients favours the adherence to therapy with either of the medications [23].

The limitations of our study include the small sample size was calculated on the basis of a relatively large effect size with respect to BPRS score. A larger sample may have shown a clear statistical difference between groups in other measures such as CGI-S and CGI-I rating. Antipsychotic drugs may increase serum prolactin [23] but we could not measure prolactin levels because of logistic constraints due to lack of infrastructure and man power. There was no scope for assessing comparative effectiveness of long-term therapy or the detection of delayed adverse events. There is poor generalizability of our results due to the strict exclusion criteria [38].

\section{CONCLUSION}

The short-term efficacy of both drugs (Olanzapine and Blonanserine) was comparable on the short term, but on long term (12 weeks) Blonanserin induced better outcomes in comparison to olanzapine. In respect to safety, Blonanserin is a promising candidate in the treatment of adult patients with schizophrenia which has low propensity to cause weight gain and metabolic abnormalities. Adherence to therapy was also good in both treatment groups. Keeping in mind the effect of blonanserin on negative symptoms and cognitive function with preferable ADR profile, large-scale long-term trials, comparing blonanserin with olanzapine and withother second generation antipychotics, have to be carried out to establish its efficacy, safety, and tolerability of schizophrenia treatment options.

Disclosure Summary: The authors have nothing to disclose.

\section{REFERENCES}

1. https://www.who.int/ [homepage on the Internet]. Geneva: World Health Organisation; @ 2019 WHO [9 April 2018; cited 2019 Dec 09]. Available from: https://www.who.int/news-room/ fact-sheets/detail/schizophrenia\#.Xd1kXqdYobg.google.

2. Gururaj G, Varghese M, Benegal $V$ et al. and NMHS collaborators group. National Mental Health Survey of India, 201516: Summary. Bengaluru, National Institute of Mental Health and Neuro Sciences, NIMHANS Publication 2016 (128).

3. Gur S, Weizman S, Stubbs B et al. morbidity and medical resources utilization of patients with schizophrenia: A case-control community-based study. Psychiatry Res. 2018; 260: 177-181.

4. Remington $G$, Addington D, Honer W et al. Guidelines for the Pharmacotherapy of Schizophrenia in Adults. Can J Psychiatry. 2017;62(9):604-616.

5. Tateno A, Sakayori T, Kim WC et al. Comparison of dopamine D3 and D2 receptor occupancies by a single dose of blonan- serin in healthy subjects: A positron emission tomography study with [11C]-(+)-PHNO. Int J Neuropsychopharmacology. 2018; 21(6):522-7.

6. Tenjin T, Miyamoto S, Ninomiya Y, et al. Profile of blonanserin for the treatment of schizophrenia. Neuropsychiatr Dis Treat. 2013; 9:587-594.

7. Stroup TS, Gray N. Management of common adverse effects of antipsychotic medications. World Psychiatry. 2018; 17(3): 341-356.

8. Lally J, MacCabe JH. Antipsychotic medication in schizophrenia: a review, Brit Med Bulletin, 2015; 114(1): 169-179.

9. Remington G, Foussias G, Fervaha G, et al. Treating Negative Symptoms in Schizophrenia: an Update. Curr Treat Options Psychiatry, 2016; 3: 133-150.

10. Ko YK, Soh MA, Kang SH, Lee Jl. The prevalence of metabolic syndrome in schizophrenic patients using antipsychotics. Clin Psychopharmacol Neurosci. 2013; 11(2): 80-88.

11. Kato $Y$, Umetsu R, Abe J, et al. Hyperglycemic adverse events following antipsychotic drug administration in spontaneous adverse event reports. J Pharm Health Care Sci 1, 2015; 1: 15. doi: 10.1186/s40780-015-0015-6. eCollection 2015.

12. Kawabe K, Horiuchi F, Ueno SI. Blonanserin, a novel antipsychotic, is suitable for treating schizophrenia associated with hyperprolactinemia: a case series. Clin Neuropharmacol. 2013; 36(6): 239-41.

13. Tenjin T, Miyamoto S, Ninomiya $Y$, et al. Profile of blonanserin for the treatment of schizophrenia. Neuropsychiatr Dis Treat. 2013; 9: 587-594.

14. Nordgaard J, Revsbech R, Sæbye D, Parnas J. Assessing the diagnostic validity of a structured psychiatric interview in a first-admission hospital sample. World Psychiatry. 2012; 11(3): 181-185.

15. Meyer JM. Pharmacotherapy of psychosis and Mania. In: Brunton LL, Chabner BA, Knollmann BC, (eds.); Goodman \& Gilman's The Pharmacological Basis of Therapeutics, 12th ed. China: McGraw-Hill Medical, 2011, 421-31.

16. http://cdn.neiglobal.com/content/pg/live/blonanserin.pdf [package Insert]. [cited 2019 Dec 12]. Available from: http:// cdn.neiglobal.com/content/pg/live/blonanserin.pdf

17. Zyprexa [package Insert]. Indianapolis (IN): Eli Lilly and Company, 2018. [cited 2019 Dec 12]. Available from: https://pi.lilly. com/us/zyprexa-pi.pdf

18. Overall JE, Gorham DR. The brief psychiatric rating scale. Psychol Rep. 1962; 10: 792-812.

19. Leon AC, Shear MK, Klerman GL et al. A comparison of sympyom determinants of patient and clinician global ratings in patients with panic disorder and depression. J Clin Psychopharmacol. 1993; 13(5): 327-31.

20. Ventura J, Nuechterlein KH, Subotnik KL et al. Symptom dimensions in recent-onset schizophrenia and mania: a principal components analysis of the 24-item Brief Psychiatric Rating Scale. Psychiatry Res. 2000; 97(2-3): 129-35.

21. Busner J, Targum SD. The clinical global impressions scale: applying a research tool in clinical practice. Psychiatry (Edgmont). 2007; 4(7): 28-37.

22. Upsala Monitoring Centre. The use of the WHO-UMC system for standardized case causality assessment [monograph on the internt]. Uppsala: Uppsala Monitoring Centre; 2005[cited 2008 Jul 7]. Availble from: http://www.who-umc.org/graphics/4409. Pdf.

23. Brown MT, Bussell JK. Medication adherence: WHO cares?. Mayo Clin Proc. 2011; 86(4): 304-314. doi:10.4065/ mcp. 2010.0575

24. Gründer G, Heinze M, Cordes J et al. NeSSy Study Group. Effects of first-generation antipsychotics versus second-gener- 
ation antipsychotics on quality of life in schizophrenia: a doubleblind, randomised study. Lancet Psychiatry. 2016; 3(8): 717-729.

25. Opler MGA, Yavorsky C, Daniel DG. Positive and Negative Syndrome Scale (PANSS) Training: Challenges, Solutions, and Future Directions. Innov Clin Neurosci. 2017; 14(11-12): 77-81.

26. Woo YS, Yoon BH, Jeon BH, et al. Switching Antipsychotics to Blonanserin in Patients with Schizophrenia: An Open-label, Prospective, Multicenter Study. Clin Psychopharmacol Neurosci. 2019; 17(3): 423-431.

27. Woo YS, Park JE, Kim DH, et al. Blonanserin Augmentation of Atypical Antipsychotics in Patients with Schizophrenia-Who Benefits from Blonanserin Augmentation?: An Open-Label, Prospective, Multicenter Study. Psychiatry Investig. 2016; 13(4): 458-467.

28. Huh L, Lee BJ. Comparison of long-term efficacy and safety of blonanserin treatment in individuals with first-episode and relapsed schizophrenia: a 3-year retrospective study, Psychiatry Clin Psychopharmacol, 2019; DOI:10.1080/2475057 3.2019.1625184.

29. Norman GR, Sloan JA, Wyrwich KW. Interpretation of changes in health-related quality of life: the remarkable universality of half a standard deviation. Med Care. 2003; 41(5): 582-92.

30. Harvey, PD, Nakamura, H, Murasaki, M. Blonanserin versus haloperidol in Japanese patients with schizophrenia: A phase 3, 8-week, double-blind, multicenter, randomized controlled study. Neuropsychopharmacol Rep. 2019; 39: 173-182.

31. Li H, Yao C, Shi J et al. Comparative study of the efficacy and safety between blonanserin and risperidone for the treatment of schizophrenia in Chinese patients: A double-blind, parallelgroup multicenter randomized trial. J Psychiatric Res. 2015; 69:102-9.

32. Kishi $\mathrm{T}$, Matsuda $\mathrm{Y}$, Matsunaga $\mathrm{S}$ et al. A randomized trial of aripiprazole vs blonanserin for the treatment of acute schizophrenia and related disorders. Neuropsychiatric Dis Treatment. 2016; 12: 3041.

33. Deepak TS, Raveesh BN, Parashivamurthy BM et al. Clinical Assessment of Weight Gain with Atypical Antipsychotics - Blonanserin vs Amisulpride. J Clin Diagn Res. 2015; 9(6): FC07-FC10.

34. Hirsch L, Yang J, Bresee L et al. Second-Generation Antipsychotics and Metabolic Side Effects: A Systematic Review of Population-Based Studies. Drug Safety 2017; 40(9): 771-781.

35. Upsala Monitoring Centre. The use of the WHO-UMC system for standardized case causality assessment [monograph on the internet]. Uppsala: Uppsala Monitoring Centre; 2005[cited 2019 Dec 11]. Availble from: http://www.who-umc.org/graphics/4409. Pdf.

36. Yang J, Bahk WM, Cho HS, et al. Efficacy and tolerability of Blonanserin in the patients with schizophrenia: a randomized, double-blind, risperidone-compared trial. Clin Neuropharmacol. 2010; 33(4): 169-175.

37. De Haan L, Van Amelsvoort T, Dingemans P, Linszen D. Risk factors for medication non-adherence in patients with first episode schizophrenia and related disorders; a prospective five year follow-up. Pharmacopsychiatry 2007; 40: 264-64. 